\title{
SER OU NÃO SER UM CURRÍCULO? CONTESTAÇÕES EM TORNO DA DEFINIÇÃO (ANTI)DEMOCRÁTICA DA BASE NACIONAL COMUM CURRICULAR
}

\author{
Ângela Cristina Alves Albino \\ Doutora em educação, professora da Universidade Federal da Paraíba \\ Rua Eduardo de Oliveira Lobo 500 - apto 103 A - Bairro: Catolé - Campina Grande -PB \\ Endereço profissional: Cidade Universitária 12, Rod. Pb-079- Campus II - UFPB - Areia/PB - \\ Universidade Federal da Paraíba \\ angela.educ@gmail.com \\ https://orcid.org/0000-0003-2452-1444 \\ Rute Pereira Alves de Araújo \\ Doutora em educação; professora da Unidade Acadêmica de Educação/UFCG; endereço \\ residencial: Trav. Frei Clementino, 32, Centro, Lagoa Seca/PB; endereço profissional: Rua Aprígio \\ Veloso, 882. Bairro Universitário - CEP: 58429-140. Campina Grande /PB \\ ruttyaraujo@gmail.com \\ https://orcid.org/0000-0001-9656-2988
}

\begin{abstract}
RESUMO
A política em torno da definição de um Currículo Nacional no Brasil vem sendo mediada por conflitos e lutas que se dão no plano político discursivo-social. A proposição de uma Base Nacional Comum Curricular foi lançada oficialmente em 2015 e muitos processos de lutas e tensões marcaram o modo de compreender um currículo perspectivado como "nacional" pelos fóruns, centros acadêmicos, associações de pesquisa. Espaços negados, lutas travadas em torno do "dizerfazer-sentir" o currículo. Nesse sentido, o presente estudo busca analisar alguns discursos produzidos em torno da compreensão de um Currículo, a partir do texto da BNCC e dos documentos encaminhados pelas associações de pesquisa, quais sejam: a ANPEd - Associação Nacional de Pós-Graduação e Pesquisa em Educação; a ABdC - Associação Brasileira de Currículo; o FNPE - Fórum Nacional Popular de Educação; bem como a posição da ANFOPE Associação Nacional pela Formação dos Profissionais de Educação - com a nota de "Repúdio ao processo de elaboração, discussão e aprovação da BNCC e a sua implementação". Nesse processo de resistência às (de)formações em torno de um "bom currículo", questionamos: Que supressões são evidentes? Quais autoridades são anunciadas em torno da afirmação do que seja um currículo? Que experiências e posições estão sendo negligenciadas nesse processo de (re)invenção de um conceito-ação curricular?
\end{abstract}

Palavras-chave: Democracia - Currículo - Educação

\section{TO BE OR NOT TO BE A CURRICULUM? CONTESTATIONS AROUND THE (ANTI) DEMOCRATIC DEFINITION OF THE COMMON CURRICULUM NATIONAL BASE}

\begin{abstract}
The politics around the definition of a National Curriculum in Brazil has been mediated by conflicts and struggles that take place in the political, discoursive and social plan. The proposal for a National Common Curricular Base was officially launched in 2015 and many fighting and tensions define the way it is understood a curriculum which is seen as "national" by forums, academic centers, research associations. Spaces denied, struggles fought around the "say-do-feel" curriculum. In this sense, the present study aims to analyze some discourses produced around the understanding of a Curriculum based on the text of the BNCC and the documents sent by the research associations, namely: ANPEd - National Association of Postgraduate and Research in Education; ABdC - Brazilian Curriculum Association; FNPE - National Popular Education Forum
\end{abstract}


as well as the point of view of ANFOPE - National Association for the Training of Education Professionals - with the note of "Refusal of the elaboration, discussion and approval process of BNCC and its implementation. "In this process of resistance to (de) formations around a "good curriculum", we ask : What suppressions are evident? What authorities are advertised around the definition of curriculum? What experiences and point of views are being neglected in this process of (re) invention of a curricular concept-action?

Keywords: Democracy - Curriculum - Education

\section{¿SER O NO SER UN CURRÍCULO? CONTESTACIONES EN TORNO DE LA DEFINICIÓN (ANTI) DEMOCRÁTICA DE LA BASE NACIONAL COMÚN CURRICULAR}

\section{RESUMEN}

La politica en torno a la definicion de un Curriculo Nacional en Brasil viene siendo mediada por conflictos y luchas que se dan en el plano politico discursivo-social. La proposicion de una Base Nacional Comun Curricular fue lanzada oficialmente en 2015 y muchos procesos de luchas y tensiones marcaron el modo de compreender un curriculo contemplado como "nacional" por los foros, centros academicos, asociaciones de investigacion. Espacios negados, luchas trabadas alrededor del "decir-hacer-sentir" el curriculum. En este sentido, el presente estudio busca analizar algunos discursos producidos en torno a la comprension de un Curriculo, a partir del texto de la BNCC y de los documentos encaminados por las asociaciones de investigacion, cuales sean: la ANPEd - Asociacion Nacional de Postgrado e Investigacion en Educacion ; la ABdC - Asociacion Brasilena de Curriculo; el FNPE - Foro Nacional Popular de Educacion; asi como la posicion de la ANFOPE - Asociacion Nacional por la Formacion de los Profesionales de Educacion - con la nota de "Repudio al proceso de elaboracion, discusion y aprobacion de la BNCC y su implementacion". En ese proceso de resistencia a las (de) formaciones alrededor de un "buen curriculo", cuestionamos: .Que supresiones son evidentes? .Que autoridades se anuncian en torno a la afirmacion de lo que es un curriculo? .Que experiencias y posiciones se estan descuidando en este proceso de (re) invencion de un concepto-accion curricular?

Palabras clave: Democracia - Curriculo - Educacion

\section{SER OU NÃO SER: EIS A CONTESTAÇÃO - PALAVRAS INICIAIS}

O propósito do estudo em questão é analisar, bem como anunciar historicamente alguns dos levantes políticos por meio de associações científicas importantes para a educação brasileira, no que diz respeito a ideia de um currículo nacional, qual seja, a BNCC - Base Nacional Comum Curricular. Nesses documentos buscaremos destacar as lutas que se dão no plano conceitual e as práticas curriculares que eles ensejam para a escola de educação básica. Trata-se de um estudo descritivo documental.

A questão em torno do ser ou não um currículo, anunciada no título, parte de Hamlet, personagem do drama de Shakeaspeare (1609), ao trazer uma questão que pode nos inspirar, em tempos de insurgência de inovação curricular. A ideia de ser ou não ser, na análise documental em torno da BNCC, não pretende evidenciar verdades em torno de um ideal de currículo ou currículo ideal, mas colocar em movimento o processo de luta hegemônica em torno do que seja um "bom currículo" ou um currículo democrático. A 
ideia que trazemos em torno do dilema existencial do clássico Hamlet, se faz no sentido de tomar ação ou se posicionar no processo de decisão curricular. Antecipamos que, nessa direção, as verdades anunciadas são mais possibilidades, ante tantas anunciadas até então, para entender o movimento de proposição política em torno do currículo.

O texto oficial da BNCC sugeriu por muitas vezes que o documento seria uma referência para a produção dos currículos locais. O próprio conceito foi posto em suspeição. Historicamente o currículo foi recebendo classificações na forma de compreendê-lo como documento, ação, prática, híbrido cultural. De todo modo, qualquer política nacional com foco na produção de conhecimento pode ser reconhecida como currículo.

O texto da BNCC encaminha orientações e determina os conhecimentos mínimos, objetivados a partir do alcance de competências. Nesse sentido ele pode sim, ser tratado como currículo oficial/oficioso. O texto oficial anuncia a BNCC como "documento de caráter normativo que define o conjunto orgânico e progressivo de aprendizagens essenciais" (2018, p.07). A perspectiva de essencializar o que contém no documento já é per si uma forma de anunciar a $\mathrm{BNCC}$ como referência maior. $\mathrm{O}$ que estaria fora do essencial? O currículo praticado nas escolas. Quando anunciam que a BNCC não é currículo, evidenciam a noção de currículo como prática quando reconhecem que currículo real é aquele feito nas escolas. Aparente democratização do discurso, apropriação de uma perspectiva mais progressista de currículo, mesmo reafirmando-o como conteúdo obrigatório nas escolas.

O texto da BNCC/2018 p.20, anuncia que "Com a homologação da BNCC, as redes de ensino e escolas particulares terão diante de si, a tarefa de construir currículo, com base nas aprendizagens estabelecidas". Um direito à construção com texto previamente determinado em detalhes que, a nosso ver, seriam da competência docente, se assim o entendemos como profissional.

É nesse contexto que assumimos a concepção de currículo como "artefato social e cultural”. Para Silva (1996, p. 83), a abordagem é mais ampla, pois incorpora as determinações sociais, históricas e a produção contextual. Assim afirma "currículo não é um elemento transcendente e atemporal - ele tem uma história, vinculada a formas específicas e contingentes de organização da sociedade e da educação”. Vislumbramos o currículo na perspectiva de um projeto que se constroi no enfrentamento das desigualdades produzidas historicamente. É um dos modos pelo qual a linguagem produz o mundo social. 
Assumimos ainda, uma compreensão de currículo como projeto complexo que envolve tessituras de saber-poder que estão arraigadas na formação sociocultural dos sujeitos de/no contexto em que se inserem. Não nos desvencilhamos da compreensão de Moreira e Silva (1997, p. 23) dos aspectos ideológicos por entendermos que a veiculação de ideias que transmitem uma visão do mundo social está vinculada aos interesses dos grupos situados em uma posição de vantagem na organização social. Nesse processo de trânsito discursivo buscamos analisar algumas reivindicações de entidades científicas e sociais e na realização de um currículo mais democrático.

Assim, ainda entendemos que a distinção já mencionada por Macedo (2006, p.02) entre currículo formal e currículo em ação tenham implicações políticas que precisam ser consideradas. Para ela, após analisar um conjunto de estudos em torno do currículo "ainda que, à primeira vista, percebamos uma virada no sentido da valorização da dimensão vivida do currículo, isso não parece ter alterado a ideia de currículo como prescrição que estava na base das teorizações tradicionais do campo". A leitura dela é pertinente no sentido de questionar se teríamos mudado apenas de forma periférica o que entendemos por currículo, introduzindo a cultura produzida na escola como parte importante a ser considerada, ou estamos mantendo a lógica de separação entre produção e implementação.

O texto da BNCC, ao mesmo tempo que afirma que o currículo é tudo que é produzido na escola, infere uma normatividade que faz pensar que o texto formal/oficial tem sua preponderância e os saberes locais são subcurriculares. Nos parece clara a relação hierárquica e a separação entre produção e implementação.

O pesquisador Michael Apple nos seus escritos da década de 90 apresenta uma posição que, inicialmente, parece obsoleta devido ao tempo. No entanto, não o é. Além de complexa traz à tona outras questões importantes (formação e valorização docente, planejamento, avaliação, áreas de saberes, etc.). Mas, segundo afirmativas do autor, ele, em princípio, não se opôs a ideia de currículo nacional nem tampouco a avaliação que a seguiu. Posteriormente, o citado autor, debatendo a mesma questão, no início do século XXI, já materializado o Currículo Nacional, nos Estados Unidos, mostrou-se preocupado com o rumo que o currículo nacional em seu país, ao evidenciar que essas questões têm importantes implicações para que repensemos algumas de nossas posições ideológicas como estudiosos do currículo, pesquisadores/as e educadores/as, 
nas tradições de desempenho e socialização que agora orientam a maior parte dos trabalhos da área, e deveriam mover-se de maneira consistente em direção a uma estrutura política e ética[...]. (APPLE, 2006, p. 216)

Nesse sentido, todo o dialogo até aqui tecido sobre as contestações das associações brasileiras, demonstra que as reflexões feitas sobre o BNCC são muito importantes para o atual estágio da educação, por ainda apresentar um déficit de financiamento por parte das políticas públicas educacionais, fato que tem implicações em todos os níveis da educação básica e superior no tocante à política curricular. Essas políticas curriculares não podem ser vistas como fraturas de um processo de formação humana. Defendemos a sua indivisibilidade assumindo uma postura de intervenção ética e política, como muito bem sugere Apple (2006).

Isso significa colocarmo-nos a favor de uma política nacional curricular que norteia a educação brasileira, mas que não se feche em si mesma, ou seja, desconsidere a pluralidade de contextos e, em particular, as (im)possibilidades de compor hegemonicamente uma política nacional de currículo. E para não dizer que não falei das flores (ainda), acreditamos que o inédito na construção de uma política nacional de currículo vem da reinterpretação e da reinvenção do formador diante da diversidade cultural que o Brasil apresenta, e é através da reinterpretação e da reinvenção que a diferença e a pluralidade se apresentam, ganham espaços e vozes, pois currículo é território de resistências, de lutas, de disputas constantes, e os documentos, que aqui nos propomos a analisar, são produtos das hibridizações que o campo da política propicia e necessita, compreendemos assim, que os textos/políticos estão sempre em processo polifônico com outros textos.

Nesse sentido de discussão curricular, Apple (2011) é autor importante para ser a base ideológica do estudo em questão. Entendemos que:

o currículo nunca é apenas um conjunto neutro de conhecimentos (...). Ele é resultado da seleção de alguém, com suas crenças particulares, ou da visão de algum grupo acerca do que seja conhecimento legítimo. Para ele "é produto das tensões, conflitos e concessões culturais, políticas e econômicas que organizam e desorganizam um povo. (Apple, 2011, p.71)

Estudos mais recentes como os de Süssekind (2015), Macedo (2014), Pereira; Oliveira (2014), Frangella (2015); Albino (2016), sobre a BNCC vão oferecer subsídios importantes para analisarmos, bem como problematizar o caráter político e epistemológico contemplado no discurso de um currículo nacional. Embora estas pesquisas tenham sido 
feitas, a partir de diferentes olhares e epistemes, evidenciam as fragilidades do texto da BNCC, bem como de todo processo de produção. Criticam o caráter privatista, a participação incisiva de instituições empresariais, o controle pedagógico por meio de avalições e estandardizada e a diluição da diversidade.

Os documentos selecionados para análise, considerou a importância das instituições representadas, bem como o compromisso assumido de forma constante com os processos de constituição, não só de ordem curricular, mas que assumem e erguem bandeiras em torno de uma educação pública, laica, gratuita e democrática como garante a Constituição Federal de 1988. O primeiro documento selecionado para análise é o encaminhado pela Associação Nacional ANPEd, bem como pela Associação Brasileira de Currículo (ABdC), pelo Ofício no 01/2015/GR, de 9 de novembro de 2015, à conselheira, professora $\operatorname{Dr}^{\mathrm{a}}$ Marcia Ângela Aguiar, presidente da Comissão Bicameral da Base Nacional Comum Curricular do Conselho Nacional de Educação (CNE). "Exposição de Motivos sobre a Base Nacional Comum Curricular".

A Associação Nacional de pós-graduação e Pesquisa em Educação - ANPED tem tido um papel preponderante na exigência de processos de pensar a educação brasileira a partir de uma concepção democrática. Assumiu um lugar de destaque no processo de contestação da BNCC, desde a 37 Reunião Nacional, realizada em Florianópolis, em outubro de 2015, se articulando a outras importantes entidades e associações que, inclusive subscrevem seus manifestos.

A Associação Brasileira de Currículo- ABdC é uma associação uma associação civil sem fins lucrativos e econômicos, caracterizando-se como pessoa jurídica de direito privado, criada em 08/06/2011. A assembléia de fundação foi realizada durante o VI Seminário Internacional: "As Redes educativas e as tecnologias: práticas/teorias sociais na contemporaneidade", na cidade do Rio de Janeiro, congregando os profissionais, pesquisadores, estudantes que realizam atividades de pesquisa e/ou docência e extensão no campo do Currículo. A Associação tem tido também papel importante junto ao GT 12 da ANPED, nesse processo de contestação curricular homogeneizadora caracterizado pela BNCC. Dessa instituição, selecionamos o documento encaminhado ao CNE no contexto das audiências públicas sobre a BNCC/2017, que se refere Posicionamento da Associação Brasileira de Currículo, representada nas audiências públicas por sua presidenta, Professora Inês Barbosa de Oliveira (UERJ/UNESA), sua secretária-geral, Rita de Cássia Frangella (UERJ) e pela associada Elizabeth Macedo (UERJ), presidente da International 
Association for Advancement of Curriculum studies (IAACS). Esse documento é importante por contextualizar o caráter (anti) democrático dos processos de participação legitimados nas conferências.

Do Fórum Nacional Popular de Educação (FNPE), extraímos a nota que manifestou sua indignação e contrariedade em relação ao texto publicado no site da revista Nova Escola "BNCC: a polarização que ensurdece" de setembro de 2018. O FNPE nasceu da a partir da desconfiguração do governo Temer ao Fórum Nacional de Educação - FNE que, desde 2010, existia com o objetivo de ampliar democraticamente os processos de decisão governamental para a educação. O ápice se refere a participação limitada, dessa instituição, na organização da terceira Conferência Nacional de Educação - Conae. O governo Temer desmontou o FNE e inviabilizou a Conae 2018, sob coordenação desse fórum.

O contexto de anulação da CONAE demandou e fez nascer o Fórum Nacional Popular de Educação - FNPE, com o objetivo de pressionar o governo federal a validar a implementação dos planos nacional, estaduais, distrital e municipais de educação para viabilizar a Conferência Nacional Popular de Educação (CONAPE 2018).

Esse processo de intervenção governamental mobilizou 35 entidades nacionais no FNPE e na I Conape cujo tem foi: "Implementar os Planos de Educação, é defender uma educação pública de qualidade social, gratuita, laica e emancipadora”. A convocatória de 10 de julho de 2017 explicita que "é inaceitável que a sociedade civil tolere intervenções unilaterais e autoritárias em espaços e processos participativos de construção, monitoramento e avaliação de políticas educacionais, sob pena do enfraquecimento irreversível da democracia brasileira".

Da Associação Nacional pela formação dos profissionais de Educação - ANFOPE selecionamos a nota sobre a BNCC: "Repúdio ao processo de elaboração, discussão e aprovação da BNCC e a sua implementação", nota de 11 de setembro de 2017.

A ANFOPE como associação surge no final da década de 1970 e como marco de origem tem a $\mathbf{1}^{\text {a }}$ Conferência Brasileira de Educação (CBE/PUC/SP), com a criação em 2/4/1980. Surge em um contexto de momentos marcantes na retomada da democratização no país. Tem princípios engendrados no movimento de educadores que reivindicavam a a construção da Base Comum Nacional, que compreendia a identidade do profissional da educação ao destacar a docência como base da identidade profissional de todo educador.

A partir da análise geral das lutas hegemônicas travadas a partir da ideia da BNCC, faremos algumas análises da prática social discursiva na perspectiva de Fairclough (2001), 
no sentido de evidenciar processos de contestação e luta em torno de um currículo democrático. Não há intenção de construir paralelos discursivos, pois não há possibilidade de negar as influências múltiplas contidas em um texto. Mas de evidenciar algumas das principais lutas travadas em torno da contestação da forma e do modo como foi conduzido o documento que regulamenta o currículo nacional. A prática social do discurso será tomada como referência, considerando que não realizaremos as outras duas etapas de análise: texto e prática discursiva. Embora dissociadas explicitar algumas hegemonias e focos de resistência é o interesse maior do estudo.

\section{ASPECTOS HISTÓRICOS EM TORNO DA ELABORAÇÃO DA BNCC}

A Base Nacional Comum Curricular - BNCC é uma política nacional de currículo que tem buscado articular os entes federados e a sociedade de um modo geral a compor a partir de 2017 uma proposta de Direitos e Objetivos de Aprendizagem e Desenvolvimento que subsidiará a produção de saberes da Educação Básica. O desenvolvimento de uma BNCC para as escolas brasileiras repercute e tenciona não só o currículo, mas todas as questões capilarizadas na proposição de saberes desse movimento de decisão que são as redes de conhecimento vinculadas à gestão escolar, à formação docente e a própria recepção discente.

O desdobramento histórico inicial da trajetória da BNCC advém do ponto de vista legal, da Constituição Federativa do Brasil/CFB/88 que explicita em seu art. 210: "Serão fixados conteúdos mínimos para o Ensino Fundamental, de maneira a assegurar formação básica comum e respeito aos valores culturais e artísticos, nacionais e regionais”. Portanto, ao mesmo tempo, em que sentimos a necessidade da construção um eixo norteador flexível de ancoragem no currículo escolar para a escola básica, rejeitamos atitudes não democráticas que cerceiam as questões postas na $\mathrm{CF} / 88$ “[...] respeito aos valores culturais e artísticos, nacionais e regionais[...]”. Isso significa que para pensar um currículo para o contexto contemporâneo faz-se necessário como frisamos acima, que o currículo não seja visto como um arcabouço de conteúdos curriculares, apenas. Mas, compreendido como um artefato que se articula em redes discursivas de significação, por conter um movimento constante de significantes que flutuam entre o que é o incomensurável (o modelo de currículo idealizado) e os demais modelos oficializados e do cotidiano, que se corporificam nos espaços educacionais formais e não formais. Esses modelos ao se articularem constroem novos sentidos para o currículo como um campo político aberto à negociação 
dos diferentes segmentos da sociedade, considerando o respeito pelas singularidades regionais do país. Passados quase 10 anos da promulgação da $\mathrm{CF} / 88$, a Lei de Diretrizes e Bases da Educação Nacional (LDB/9394/96) é promulgada e traz de forma ampliada e com alguns detalhes à compreensão do que seria uma base nacional comum, no Art. 26:

Os currículos do Ensino fundamental e Médio devem ter uma base nacional comum, a ser complementada em cada sistema de ensino e estabelecimento escolar, por uma parte diversificada, exigida pelas características regionais e locais da sociedade, da cultura, da economia e da clientela.

Nesse intercurso como se pode ver, não houve avanços do ponto de vista da formulação objetiva da Base Nacional Comum, além do que estava explicitado na CF/1988 e na LDB/9394/96, apenas, alguns documentos foram sendo pensados na perspectiva de orientação curricular, no cenário educacional brasileiro, entre eles, destacamos a elaboração e difusão dos Parâmetros Curriculares Nacionais (PCNs- 1997 a 2000), documentos vistos como:

[...] referência básica para a elaboração das matrizes de referência. Os PCN's foram elaborados para difundir os princípios da reforma curricular e orientar os professores na busca de novas abordagens e metodologias. Eles traçam um novo perfil para o currículo, apoiado em competências básicas para a inserção dos jovens na vida adulta; orientam os professores quanto ao significado do conhecimento escolar quando contextualizado e quanto à interdisciplinaridade, incentivando o raciocínio e a capacidade de aprender [...].

Contudo, evidenciamos que a partir de 1997 foram feitas composições curriculares, como foi o caso dos Parâmetros Curriculares Nacionais - PCNs para o Ensino Fundamental que vai do $1^{\circ}$ ao $5^{\circ}$ ano e, em 1998 são lançados mais dez volumes para a segunda fase do Ensino Fundamental $6^{\circ}$ ao $9^{\circ}$ ano. Ainda, nesse processo de produção, no ano 2000, são lançados os Parâmetros Curriculares Nacionais para o Ensino Médio PCNEM em quatro volumes para orientar o professor na produção de novas metodologias e abordagens de conhecimento, a saber: Linguagem Códigos e suas tecnologias, Ciências da Natureza e suas tecnologias, Ciências Humanas e suas tecnologias e Matemática e suas tecnologias.

As tensões que se geraram em torno da construção de uma Base Nacional Comum Curricular permeiam a própria definição da palavra currículo e o seu vasto campo de estudos, pesquisas e concepções que vêm sendo construídas ao longo dos anos em alguns grupos de pesquisas brasileiros, bem como através das principais associações de pesquisa 
do país. É sabido que a construção de uma base comum curricular vem sendo anunciada desde a Constituição Federal, a carta constitucional já orienta para a definição de uma base nacional comum curricular ao estabelecer, no Artigo 210, que: "serão fixados conteúdos mínimos para o ensino fundamental, de maneira a assegurar formação básica comum e respeito aos valores culturais e artísticos, nacionais e regionais" (BRASIL, 1988 - itálicos nossos).

Como é possível observar a ideia de um currículo nacional comum a partir da delimitação de conteúdos mínimos que "assegurem" uma formação básica comum são apresentadas já na Constituição (1988), mais adiante a ideia de uma Base Comum é referendada na Lei de Diretrizes e Bases da Educação Nacional - LDB, em seu artigo $26^{\circ}$, assim ampliado:

Os currículos da educação infantil, do ensino fundamental e do ensino médio devem ter base nacional comum, a ser complementada, em cada sistema de ensino e em cada estabelecimento escolar, por uma parte diversificada, exigida pelas características regionais e locais da sociedade, da cultura, da economia e dos educandos. (BRASIL, 1996)

Além desses documentos legais - CF e LDB - ao longo de nossa história outros documentos e diretrizes curriculares foram se constituindo as custas de embates, rejeições e adesões de diversificados grupos e associações de pesquisa a exemplo, dos PCNs Parâmetros Curriculares Nacionais para o Ensino Fundamental (1997), o RCNEI Referencial Curricular Nacional para a Educação Infantil (1998), mais tarde as, DCNEB Diretrizes Curriculares Nacionais para a Educação Básica e DCNEIS - Diretrizes Curriculares Nacionais para a Educação Infantil (2010), entre outros, até chegarmos a proposição da BNCC em 2015 e o percurso tenso que permeou o decurso de elaboração de suas três versões.

Esse breve apanhando histórico inquieta em vários aspectos, um deles é o pouco espaço temporal que separa a constituição de um documento e o advento de outro, que implica além de recursos e investimentos públicos, o desrespeito aos professores e professoras de nosso país, suas lutas, seus contextos históricos, políticos, sociais e laborais, bem como seus processos formativos. A compreensão limitada em torno das conquistas históricas apresentadas na Constituição Federal e LDB - 9394/96 quando se trata de um currículo nacional. Para além dessas questões um quesito que se torna latente na produção da BNCC são os processos de tensão e resistência que configuram o olhar representativo das principais associações de pesquisa do país, vários documentos foram encaminhados ao 
CNE - Conselho Nacional de Educação, a exemplo da crítica que ANPED tece à metodologia de elaboração da BNCC, que ao privilegiar o trabalho de especialistas, relega e/ou inferioriza o diálogo com as comunidades escolares, no intento de homogeneização a partir das matrizes curriculares. Além disso, a BNCC, de acordo com esse documento da ANPED, é inspirado em experiências de centralização curricular em voga em outras realidades distintas da brasileira, como o modelo do Common Core Americano, o Currículo Nacional desenvolvido na Austrália, e a reforma curricular chilena. (ANPED, 2017).

A ANFOPE, se encaminha nessa perspectiva, e repudia dentre alguns conceitos relevados na BNCC a concepção de "competências" ao entender que esse modelo desrespeita “os Documentos da BNCC produzidos pelos estados e ainda retroagiu ao modelo de competências das DCN de Formação de Professores (Resolução CNE $n^{\circ}$ 1/2002), revogada pela Resolução CNE n 2/2015”, assim como a ANPED, a ANFOPE também ponderou sobre a separação do Ensino Médio das outras etapas e modalidades da Educação Básica, desconsiderando assim, as Resoluções do CNE. (ANFOPE, 2017).

Os documentos acima citados, reconhecem que as versões da $\mathrm{BNCC}$ não reconhecem as dimensões da diversidade da educação brasileira, traduzindo-se em um mecanismo antidemocrático de desrespeito, sobretudo, as diferenças existentes em nosso país.

Dentro do "pacote" de medidas alavancadas pelo MEC a partir da BNCC, algo que tem inquietado e tensionado o debate está no que concerne a formação dos professores, tanto na linha da formação inicial, quanto continuada, assim, em manifesto, as entidades educacionais se posicionam frente às essas medidas anunciadas pelo Ministério da Educação, dentre elas o - programa "Residência Pedagógica" que de acordo com o manifesto ocorre de modo impositivo, sem o diálogo com a academia, desconsiderando e/ou subestimando programas já existentes a exemplo do PIBID, ao passo que enaltece a formação a distância como mecanismo de aligeiramento que reverbera de modo contundente na precarização da docência e conseguinte dos cursos de licenciatura como um todo.

Com base nas exposições, aqui brevemente apontadas, buscaremos ao longo desse artigo discorrer de modo mais analítico/reflexivo sobre o Manifesto das entidades ANPEd (2017) e ANFOPE (2017) sobre o processo de construção da Base Nacional Comum Curricular versus os conceitos de democracia e currículo. 
Sentimos, a partir da leitura dos documentos supramencionados, bem como mediante a atual conjuntura política do país, a necessidade de refletir, acerca das concepções de currículo e democracia que vêm se desenhando nesse cenário, para isso tomamos como referências a perspectiva de Análise Crítica do Discurso/ ACD nos reportando apenas a terceira fase de análise que recai sobre a prática social. Buscamos analisar de forma geral, em alguns documentos de associações científicas as relações e estruturas hegemônicas que constituem a que constituem a matriz dessa instância particular da prática social e discursiva Fairclough (2001).

A Análise Crítica do Discurso (ACD) de Fairclough (2001) pode ser entendida, ao mesmo tempo, como uma teoria e um método de análise. Suas proposições indicam que questões sociais e políticas-chave têm um caráter parcialmente linguístico-discursivo. Percebemos a teoria de Fairclough (2001) como dialética, à medida que considera o discurso, por um lado, moldado pela estrutura social e, por outro, constitutivo da estrutura social.

O conceito de hegemonia é foco da Análise Crítica do Discurso por perspectivar mudança, "a hegemonia é um contínuo processo de formação e suplantação de um equilíbrio instável" (GRAMSCI, 1988, p. 423), bem como aborda o discurso como meio de se lutar pelo consenso, mesmo entendendo-o no processo de instabilidade.

A opção por trabalhar com a ACD - Análise Crítica do Discurso do linguista britânico Fairclough (1999, 2001, 2003), se dá por compreender que, as questões sociais têm um caráter parcialmente linguístico discursivo. O autor considera o discurso numa perspectiva dialética moldado pela estrutura social, bem como constitutivo dessa estrutura. O discurso significa e produz significados, e muitas vezes esses sentidos são demasiadamente naturalizados e/ou opacados.

Nesse percurso, as ordens do discurso podem ser entendidas "como equilíbrio instável, consistindo de elementos que estão constantemente abertos para serem redesenhados à medida em que são articulados ou desarticulados", naquilo que Fairclough (2001, p.159) entende como percurso de luta hegemônica. A prática discursiva para Fairclough (2001, p.126) é um "modo de luta hegemônica, que reproduz, reestrutura ou desafia as ordens de discurso existentes".

Quando Fairclough (2001, p. 90) utiliza o termo "discurso", o faz considerando o uso da linguagem como forma e prática social. O discurso é um "modo de ação, uma forma 
em que as pessoas podem agir sobre o mundo e, especialmente, sobre os outros como, também, um modo de representação"; o discurso pode ser "moldado e restringido pela estrutura social", enquanto significa e produz significados.

\section{A BNCC E AS ENTIDADES/ASSOCIAÇÕES BRASILEIRAS DE EDUCAÇÃO - TENSÕES E DESAFIOS}

A seguir apresentaremos um panorama geral do conteúdo abordado nos documentos elaborados pelas entidades científicas que, a nosso ver, tem representatividade no processo de contestação da BNCC. Não negamos as demais associações que também deram vazão e/ou assinaram essas contestações a exemplo da Associação Nacional de Política e Administração da Educação. Mas o recorte é representativo e amostral.

\section{ASSOCIAÇÃO NACIONAL DE PÓS-GRADUAÇÃO E PESQUISA EM EDUCAÇÃO - ANPED E ASSOCIAÇÃO BRASILEIRA DE CURRÍCULO - ABDC}

A ANPEd e a ABdC como associações científicas se destacam pelo processo incansável de luta em favor de um currículo pensado a partir de uma perspectiva mais democrática de participação de atores/sujeitos sociais, desde a política de criação da BNCC. Assim, esboçaremos algumas reivindicações de sentidos em torno de um currículo, a partir de alguns do conjunto de atos/documentos que foram produzidos por estas associações.

Acreditamos que estas associações têm sido instâncias e possibilidades de prática social e discursiva pelas contestações e teor de suas reivindicações, bem como pelos efeitos que elas podem trazer para (re)pensarmos as nossas políticas curriculares sob uma ideia de representação democrática e "nacional" (FAIRCLOUGH, 2001, p.289).

Os documentos selecionados trazem um recorte temporal específico em torno do processo de construção da BNCC. O primeiro intitulado: "Exposição de Motivos sobre a Base Nacional Comum Curricular", foi produzido em novembro de 2015, ainda processo inicial de produção da BNCC, por meio do GT 12 - Currículo e com apoio da Associação Brasileira de Currículo. Este documento já se manifestava contrário ao documento orientador de políticas para a Educação Básica apresentado pela SEB/MEC a consulta pública que ensejava a Base Nacional Comum Curricular.

O documento da $\mathrm{ABdC}$ "Posicionamento da Associação Brasileira de Currículo, 
representada nas audiências públicas” por sua presidenta, Professora Inês Barbosa de Oliveira. O Documento foi produzido e encaminhado ao CNE no contexto das Audiências públicas sobre a BNCC /2017.

Foi a partir da 37 ${ }^{\mathrm{a}}$ Reunião Nacional, realizada em outubro de 2015 em Florianópolis que a ANPED vem produzindo documentos em que anunciam sua posição crítica, no que diz respeito a BNCC. A assembleia geral aprovou a moção contrária a ideia de base que se anunciava. O documento foi proposto pelos GTs 12 - Currículo e 23 Educação ambiental. Dentre os argumentos apresentados o fato de não contemplar as dimensões da diversidade brasileira, o retrocesso quanto à compreensão de uma política ambiental, forma e o processo metodológico, bem como as implicações nos processos de avaliação da aprendizagem, na autonomia e formação dos docentes.

O Ofício n. ${ }^{o}$ 01/2015/GR que se intitula: "Exposição de Motivos sobre a Base Nacional Comum Curricular" de 09 de novembro de 2015, foi encaminhado a Conselheira Professora Doutora Marcia Ângela Aguiar, Presidente da Comissão Bicameral da Base Nacional Comum Curricular. O documento foi produzido por uma equipe interinstitucional de pesquisadores vinculados a ANPEd por meio do GT 12 e a ABdC, no sentido de buscar estabelecer um canal de diálogo com a SEB - Secretaria de Educação Básica do MEC Ministério da Educação concernente a "consulta pública" ocorrida em setembro de 2015 considerada imprópria ante as finalidades apresentadas. O documento manifesta disposição para diálogo, bem como compromisso histórico de desenvolvimento educacional a partir de "princípios de participação democrática, liberdade e justiça social". Assinaram a professora Inês Barbosa de Oliveira, na época presidente da $\mathrm{ABdC}$ e Maria Margarida Machado presidente da ANPEd.

O documento, além boa organização didática tornou explícito as questões concernentes ao currículo, que estavam em jogo no momento ainda das audiências públicas. Foram, ao todo, elencados nove motivos explicados e articulados para justificar a forma e o conteúdo da BNCC à época.

Alguns marcadores explícitos de assimetria e hierarquia de poder são postos em discussão a partir do documento formulado pela ANPEd em parceria com a ABdC. Podemos destacar entre eles: o papel do especialista determinando os conteúdos e objetivos de aprendizagem, sem que houvesse tempo para as escolas estudarem e oferecerem devolutivas mais sistematizadas. Conferências sem representatividade e ocorridas de forma aligeiradas. A ausência dos estudantes e representações estudantis é quase nula nesse 
processo. Temos assim um currículo sem a voz discente.

O conteúdo midiático tratou de representar essa participação democrática evidenciando que havia um canal aberto e cerca de doze milhões de acesso, embora não tenhamos nenhuma evidência de tabulação ou devolução sistematizada dessa consulta inicial sobre a BNCC. Para Fairclough (2001), as ideias tidas como "verdade" pelo senso comum estão vinculadas aos sistemas de poder que as sustentam e a relação é circular. Nesse sentido de produção discursiva da BNCC com sua regulamentação, distribuição, circulação e operação de discursos, tem em vista a formação de um regime da "verdade". Essa saída midiática para modelar um discurso democrático constituiu-se um marco em todo processo.

As associações ANPEd e ABdC vão requerer, no documento, um currículo que atenda a finalidade educacional prevista na Constituição Federal de 1988: escola pública, universal, gratuita, laica e de qualidade para todos. Assim, fica justificado o atendimento ao princípio da diversidade referendado na LDB - Lei de Diretrizes e Bases da Educação Nacional 9394/96.

A versão primeira que estava sob consulta é avaliada no documento como imprópria por descaracterizar o estudante em sua condição de diferença, bem como desumanizar e reduzir o docente em sua condição criativa. A autonomia docente é tencionada pela padronização curricular por meio da avaliação externa e hierarquizadora que utiliza a lógica das competências como medida de controle e redução pragmática do que possa vir a ser o conhecimento.

Outra crítica pertinente é que reduz os conteúdos locais à parte diversificada. Nessa lógica hierarquiza-se os conhecimentos e a vida que corre na existência concreta da criança subalternizando-a na relação com os conhecimentos científicos. O histórico acumulado alheio parece ser mais importante do que ela, como produtora cultura, expressa diariamente.

Uma reivindicação importante apresentada na exposição de motivos foi argumentada pelo processo histórico de lutas em torno da escola pública e democrática ao se referir ao projeto político-pedagógico das escolas. $\mathrm{O}$ documento reitera o momento de produção do PPP como instância privilegiada de decisão curricular, conforme os Art. 12, 13 e 15 da LDB 9394/96. Estudos como os de Albino (2010, 2015) sobre autonomia e produção curricular mediadas pelos projetos político-pedagógicos das escolas podem ser possibilidades fundamentais de construção de um currículo baseado na/com a realidade da 
escola, bem como ser um bom exercício democrático nessas instituições.

O documento, no processo de exposição de motivos, evidencia de forma geral, que não podemos pensar em um modelo de educação para a diversidade sem valorização da autonomia e a riqueza local em que são produzidos esses conhecimentos. Cada escola é única em sentidos, anseios e necessidades. Um currículo que subalternize esses significados parece não perspectivar uma formação para cidadania e movimento crítico democrático.

Assim, há um chamado para a consolidação do papel dos conselhos entidades, associações locais, parcerias com universidades na construção coletiva, socialmente referenciada da escola pública, gratuita e de qualidade para todos. Essa seria uma matriz referenciada de currículo considerando sujeitos, espaços, diferentes em/com suas diferenças.

$\mathrm{O}$ documento encaminhado pela $\mathrm{ABdC}$ ao $\mathrm{CNE}$ no contexto das audiências públicas em setembro de 2017 é elucidativo quanto ao modo de dizer explicitar como pensam/anunciam o currículo. A problematização sobre a compreensão do que seja uma base como algo em que se erige alguma coisa, uma fundação não corresponde a um documento que define resultados e habilidades de saída dos alunos. Ele aponta para o lugar que se quer chegar e não de onde se parte.

A base nesse sentido, ou perspectivada a partir de um olhar mais crítico poderia sugerir que a base de um currículo seja o alimento para crianças com fome, transporte para aqueles que ainda caminham por horas para chegar à escola, saúde para as crianças com pediculose e escabiose, segurança para os que atravessam tiroteiros para conseguirem chegar ao seu destino. Esses são elementos de base, sobretudo quando pensamos na produção de conhecimento e na complexidade/totalidade/desigualdade dos sujeitos.

O documento ainda faz críticas ao conteudismo e disciplinarismo, a negação da diferença, que fere o princípio da experiência. Conforme a nota da ABdC (2017), uma política de currículo precisa assegurar a máxima colocada por Santos (2003, p.56) "o direito a ser iguais quando a nossa diferença nos inferioriza; e temos o direito a ser diferentes quando a nossa igualdade nos descaracteriza". Nesse sentido precisamos de um currículo que reconheça a necessidade de uma igualdade, as diferenças e que não produza, alimente ou reproduza as desigualdades.

A ideia disseminada pelo texto e organizadores da BNCC de que um currículo 
centralizado em nível nacional representa a melhor alternativa, também foi contestada. Diane Ravich que trabalhou na gestão de Bush nos EUA é citada como exemplo por vir denunciando em seu blog que não houve redução de desigualdades nos estados americanos que fizeram opção por currículo centralizado.

\section{FÓRUM NACIONAL POPULAR DE EDUCAÇÃO - FNPE}

O Fórum Nacional Popular de Educação - FNPE, já é em si uma forma de resistência às arbitrariedades do governo Temer pós golpe (2016-2018), ao negar as formas de representação democrática da Conferência Nacional de Educação - CONAE. Em julho de 2017, vinte entidades que faziam o Fórum Nacional de Educação - FNE entregaram um documento à comissão de Educação, Cultura e Esporte do Senado anunciando renúncia coletiva do FNE. Tais entidades criticavam a portaria $\mathrm{n}^{\circ} 577$ de 27 de abril de 2017 do Ministério da Educação que excluía entidades históricas do campo educacional e, ao mesmo tempo aumentando a bancada governamental o que feria os princípios de uma constituição equilibrada e, sobretudo democrática, do FNE e comprometia assim a organização da Conferência Nacional de Educação - CONAE/2018.

Assim, a partir das entidades nasceu o FNPE e a construção da Conferência Nacional Popular de Educação (CONAPE) como movimento de resistência ao formato estabelecido pelo governo da época.

A documento selecionado do FNPE, para alocarmos nesse processo de contestação histórica da BNCC foi uma nota de indignação e contrariedade lançada pelo fórum em resposta ao texto publicado no site da Nova Escola "BNCC: a polarização que ensurdece", de 20 de setembro de 2018, por Paula Peres e Laís Semis. A matéria veiculada na revista afirmava que faltava abertura e respeito nas audiências públicas, mas assumia de forma evidente que faltava muito mais "competências socioemocionais" dos professores, assim como de quem protestava contra a BNCC na relação estabelecida entre especialistas e organizadores que dirigiam as conferências.

A nota do FNPE denuncia a defesa de um posicionamento político diante da pauta em foco, inclusive em outras matérias veiculadas pela mesma revista. Nesse sentido, indica a tentativa de deslegitimar a atuação de professores e pesquisadores que se posicionavam contrários à BNCC.

A nota destaca citações da matéria jornalística tais como: "educadores perdem o foco", "falta diálogo e empatia no setor que mais prega e pede o diálogo", "disputa para ser 
ouvido e falar mais alto", o "inimigo" e "merece ser massacrado". A luta pela participação ou o pronunciamento contrário a BNCC, também precisaria ser reconhecida como participação qualificada de um processo de produção curricular em que forças hegemônicas e não hegemônicas entram em cena para conquistar espaço e poder político para anunciar, o que pode vir-a-ser, o melhor conhecimento.

A nota denuncia que, os processos conduzidos pelo governo costumavam priorizar a segurança e os espaços físicos evidenciavam isso em seus portões fechados, participação restrita, tempo corrido, acessos exclusivos, pessoas barradas. Nesse sentido, evidencia desequilíbrio no processo, justificado por um governo ilegítimo que já aprovava pautas sem a participação democrática. Destacamos a importância desse documento à insistente necessidade de participação democrática, já reivindicadas pela ANPEd e $\mathrm{ABdC}$ dos atores/sujeitos que deveriam estar no centro da formulação política educacional, sobretudo quando se trata de currículo. O documento é assertivo quando se trata de formulação curricular, assim os resultados se apresentam "em desfavor do direito dos estudantes e do respeito aos educadores".

$\mathrm{O}$ artigo publicado pela revista Nova Escola, nesse sentido, vai requerer uma isonomia que não existe conforme nota do FNPE, que utiliza aportes freireanos da impossibilidade neutralidade nas disputas políticas.

É importante considerar o contexto na produção do discurso, a partir do que ressalta Fairclough (2001, p.71):

Os textos postulam sujeitos intérpretes e implicitamente estabelecem posições interpretativas para eles que são 'capazes' de usar suposições de sua experiência anterior, para fazer conexões entre os diversos elementos intertextuais de um texto e gerar interpretações coerentes. Não se deve entender com isso que os intérpretes sempre resolvam plenamente as contradições de textos. (FAIRCLOUGH, 2001, p. 171, grifos do autor)

Assim, o documento do FNPE contesta uma matéria jornalística de fundo educacional, que favorece a instância de proposição curricular sem buscar compreender os gritos e tentativas de diálogo dos sujeitos/atores que dão substância ao conhecimento, quais sejam: professores e estudantes.

\section{A ANFOPE E SUA NOTA DE REPÚDIO AOS PROCESSOS DE ELABORAÇÃO, DISCUSSÃO, APROVAÇÃO E IMPLEMENTAÇÃO DA BNCC}


A Associação Nacional pela Formação dos Profissionais da Educação - ANFOPE - é uma entidade que nasce no campo das lutas e das reformas dos cursos de formação de educadores na década de 1970, levantando a voz frente a onda tecnicista que ameaçava o campo educacional e mais tarde, nos anos 1980, se fortalece mediante sua atuação presente no campo da formação de profissionais da educação.

Com base em sua história de lutas a ANFOPE se posiciona sobre a BNCC em um documento de três páginas intitulado - "Repúdio ao processo de elaboração, discussão e aprovação da BNCC e a sua implementação", nesse documento a Associação reflete sobre o seu histórico de lutas passadas e conquistas de direitos, ponderando acerca do cenário atual da política brasileira, mediante o clima de instabilidade política e econômica e de ampla crise institucional que vivemos, observando que estamos passando por um momento marcado por imposições de medidas que eclodem incontestavelmente em retrocessos à educação. De acordo com o posicionamento da ANFOPE a adoção de políticas que retiram direitos e desmontam estruturas e ações nos diversos campos da vida social que impactam diretamente o financiamento para a educação e as políticas nacionais de formação de professores. Nesse sentido: "a Anfope - Associação Nacional pela Formação dos Profissionais da Educação, reafirma seu posicionamento crítico, manifestando seu repúdio ao processo de elaboração, discussão e aprovação da BNCC." (ANFOPE, 2017).

Nesse documento, a ANFOPE, após participação nas cinco audiências sobre a BNCC que foram coordenadas pelo Conselho Nacional de Educação, se opõe a centralização curricular e uniformização que a Base equivocadamente formula, não considerando, segundo essa associação, a múltipla diversidade das escolas brasileiras e "ethos de seus alunos". O documento continua com a crítica ao processo de produção da Base que resulta em uma terceira versão que desconsidera as críticas propositivas das entidades educacionais, privilegiando alguns setores empresariais que têm interesse na padronização do ensino como meio de atender a fins mercadológicos. (ANFOPE, 2017).

Nesse sentido, a ANFOPE pondera que não houve discussões nas escolas, em cada município e estado brasileiro, "mas que já possui, antes mesmo de aprovada, um Guia de Implementação, desvelando, assim, seu caráter impositivo e a falácia de audiências que apenas simulam um diálogo com a nação." (ANFOPE, 2017).

Com base nas contestações da ANFOPE frente a eminente ameaça à democracia que, especialmente, a terceira versão da BNCC representa e, coadunando com a 
perspectiva dialética do discurso de Norman Fairclough (2001, p. 94) compreendemos que no terreno das práticas os seus "eventos contraditórios e em luta", são representativos, nesse contexto específico, de “[...] uma relação complexa e variável com as estruturas as quais manifestam apenas uma fixidez temporária, parcial e contraditória”, isso ocorre porque o discurso como prática política e ideológica, de acordo com Fairclough (2001) é capaz de constituir, naturalizar, manter e transformar os significados.

Assim, ao longo do processo de construção da Base, a ANFOPE esteve presente e denuncia, através do documento aqui analisado, a verticalidade que permeou boa parte do processo. Entendemos com Fairclough (2001) que esse processo se configura em significados gerados mediante a articulação da prática política e das ideologias a ela subjacentes, uma vez que as ideologias são formadas em relações de poder, assim interpretadas como campo de lutas.

A posição da ANFOPE nos remete ao falseamento democrático que perpassa todo o processo de tessitura do documento tendo nas audiências, promulgadas durante o processo, um pseudo canal de discussão uma vez que as proposições das instituições não foram ouvidas. Além dessa questão, a ANFOPE considera que a adoção de matrizes curriculares homogeneizadas ameaçam o princípio de autonomia dos estados e municípios em relação a construção de seus Projetos Político Pedagógicos, uma vez que esses terão que se pautar na Base. O princípio de autonomia também é vilipendiado quanto a formação dos profissionais da educação que terão seus currículos reformulados, contemplando a BNCC, por essa razão a ANFOPE reitera que:

Outro aspecto que merece nosso enfrentamento é a adequação automática da formação docente aos itens da BNCC, ferindo a autonomia das instituições formadoras, restringindo a formação de professores em sua dimensão cognitiva, a um contexto, em que a educação privada e a modalidade de educação a distância avançam de maneira assustadora no campo das licenciaturas e da formação continuada dos profissionais da educação, em que campeia a adoção de material didático previamente estabelecido, atendendo a interesses de fundações privadas. (ANFOPE, 2017).

Dentro desse "pacote" a concepção de "competências" levantada na BNCC retroage em discussões e avanços que as entidades já consideravam superadas. Nesse sentido e complementando o conjunto de arbitrariedades que compõem os processos de tessitura, discussão e implementação do referido documento levantadas pela ANFOPE, destacamos: 
a. "avaliar e punir" - estudantes, professores e escolas - mediante o fortalecimento das avaliações nacionais em larga escala, cujos resultados servirão como base para remuneração e controle do trabalho docente, recaindo no enfraquecimento da autonomia docente;

b. A Educação Infantil não terá um sentido em si mesma, mas servirá de ponte para o Ensino Fundamental, assumindo assim, um papel escolarizante que desconsidera as especificidades da infância e as suas necessidades.

Compreendemos que a prescrição curricular - vista de modo unívoco - na perspectiva exclusiva dos documentos, no caso a BNCC, está mais preocupada com a padronização do "currículo" e essa atitude implica a negação da diversidade humana e cultural que temos, podendo ser traduzida como um mecanismo de força e poder, cuja tentativa maior é homogeneizar as massas, negando a diferença (PEREIRA, 2010).

Pode-se empreender, ainda, a partir da análise social do discurso e a sua concepção tridimensional que o documento/texto, as práticas discursivas e sociais estão intrinsecamente conectadas.

Esperançamos que, no contexto da prática social, (espaço amplo de (re) significações), as experiências dos sujeitos e suas multifaces, a polifonia de suas vozes, a policromia de suas culturas e etnias, bem como mediante os múltiplos contextos escolares de nosso país as "definições” da BNCC sejam ressignificadas.

No entanto, não se pode negar a força do texto/documento que, segundo Fairclough (2001, p. 103) “[...] são em geral altamente ambivalentes e abertos a múltiplas interpretações".

Os intérpretes, em suas práticas discursivas (processos que envolvem produção, distribuição e consumo textual) consomem diferentemente esses textos mediante a complexidade e diversidade de seus contextos e esse consumo, como a produção, pode ser de acordo com Fairclough (2001) individual ou coletiva.

A ANFOPE como artefato da coletividade exerce esse papel de interpretante, mediante o documento, aqui analisado, no entanto, não se pode negar as estruturas de poder que se formulam nesse processo, pois "as práticas discursivas são investidas ideologicamente à medida que incorporam significações que contribuem para manter ou reestruturar as relações de poder.” (FAIRCLOUGH, 2001, p. 121).

Portanto, é no campo das práticas sociais que os discursos podem ser 
reconfigurados mediante ações contra hegemônicas que culminam em mudanças sociais e culturais (Fairclough, 2001).

Mediante o exposto no cabe (escolas/sociedade) coragem para redesenhar a "prescrição curricular" (texto) com as cores da resistência e da luta que são marcas de nossa gente. É no terreno das práticas, no chão da escola, que o currículo se produz e os textos legais são reinterpretados à luz da existência e das vivências singulares dos sujeitos que fazem a escola.

Entendemos, portanto, que as políticas não podem ser concebidas como processos estanques, mas estão sempre, em "processo de vir a ser", sendo assim, são múltiplas as considerações, ponderações e leituras, possíveis de serem realizadas por um público de leitores múltiplo, plural. Esta característica coloca a escola em um espaço de interpretação contínua, democrático.

A BNCC, de acordo com o texto da terceira e última versão, assim como os documentos de repúdio ao documento, aqui apresentados, se constituem elementos de poder ao passo que buscam a partir de seus discursos legitimar um lugar de fala e identidade, que não consegue corresponder a inteireza e singularidades do outro a quem esse currículo diz se endereçar, mas não consegue contemplar. Há diferenças que não são consideradas nos documentos, há espaços e identidades que fazem currículo independente das intenções da BNCC, é momento de indagar quem são esses outros que a base não consegue alcançar? A quem foi outorgado o poder de dizer o que é currículo? Ao passo que possuo assertivas sobre o conceito do que é currículo e o que o constituí, engessamos e desconsideramos tudo que dessa concepção destoa.

Ao intentar, desejar uma base comum se nega os fazeres, pensares e dizeres que não coadunam com o comum, há uma rejeição a heterogeneidade e diversidade, marcas de nosso país. Será que os posicionamentos das associações dão conta de todos os currículos existentes no contexto nacional? Temos necessidade de uma Base? Quais as urgências educacionais do nosso país? A seguir formulamos um quadro geral das contestações apresentadas nos documentos e que, em alguma medida começam a responder nossos questionamentos.

\section{QUADRO GERAL DA SÍNTESE DOCUMENTAL - ANPEd - ABdC - FNPE - ANFOPE}

$\begin{array}{lll}\text { Associação/Fórum } & \begin{array}{l}\text { Currículo negado - (referência } \\ \text { BNCC) }\end{array} & \text { Currículo reivindicado } \\ & \text { Uniformização. } & \text { Que atenda a finalidade prevista }\end{array}$




\section{ANPEd}

AbdC
Hegemonia/única forma de ver os estudantes, aprendizagens, escolas, trabalho dos professores, avaliações.

Identidades serializadas.

Impróprio à escola pública universal, gratuita, laica e de qualidade para todos

Descaracterização do estudante em sua condição de diferença.

Desumanização do trabalho docente em sua condição criativa e desconsideração da complexidade da vida na escola.

Lista de objetivos conteudinais a serem aprendidos.

Competência, qualificação profissional, empregabilidade e avaliação de desempenho.

Centralidade conferida à lógica do ensino de conteúdos, tidos como universais/ Seleção por especialistas.

Orientações estruturadoras" para "redes e escolas" e o estabelecimento detalhado de relações teóricas, de valores, de conhecimentos, um "currículo mínimo" Nacional como homogêneo - perigo para democracia.

Conteúdos locais reduzidos a parte diversificada.

Lógica do ensino de conteúdos, tidos como universais e à sua seleção por especialistas.

O internacional como referência de força.

Metodologia da construção da Base: pressa, indicação e na Constituição Federal de 1988- escola pública universal, gratuita, laica e de qualidade para todos.

Diversidade como princípio fundamental ao projeto de nação democrática expresso na Constituição Brasileira e que se reflete na LDB/1996.

Respeito e valorização da pluralidade, fundamento da educação nas sociedades democráticas. Flexibilidade na norma curricular.

$\mathrm{O}$ direito à igualdade for pensado em concomitância com o direito à diferença e o respeito à pluralidade.

A educação não se esgota em aprendizagem, inclui processos individuais e sociais desenvolvidos e vivenciados "ao longo da vida".

Os processos locais e autônomos não podem nem devem ser percebidos como "parte diversificada".

Direitos de aprender e de ser sujeito do próprio processo educativo.

Espaço legal e democraticamente garantido: os projetos político-pedagógico locais (LDB/1996; Art. 12, 13, $15)$.

Educação para diversidade valoriza a autonomia e a localidade.

Consolidação do papel dos conselhos, entidades, associações locais, parcerias com universidades na construção coletiva, socialmente referenciada da escola pública, 
indefinição.

Ruptura com a necessária autonomia docente que a padronização curricular por meio da avaliação externa e hierarquizadora.

Compreensão tecnicista e ultrapassada de currículo define resultados, metas e habilidades.

A racionalidade que guia essa forma de fazer currículo é a de estabelecer o que se espera na saída.

Indica um caminho único.

Tratar igualmente os desiguais

Produção Curricular com participação restrita e limitada, acessos exclusivos, pessoas barradas, poucos estados abrangidos.

Forma autoritária.

Resultados comprometidos, portanto, em desfavor do direito dos estudantes e do respeito aos educadores.

Desequilíbrio no processo.

Nega um currículo que se formula

- documento - e nega a participação propositiva das instituições educacionais. gratuita e de qualidade para todos.

Defesa da pluralidade nacional valorização da localidade, da diversidade, das negociações de sentidos, autonomamente, em cada escola, em cada rede, é o modo como entendemos qualquer criação de "currículo".

Oferecer possibilidades DIVERSAS/PLURAIS de proposta e experiência curricular a alunos diferentes/desiguais é necessário para promover a equalização social e a redução das desigualdades.

As escolas não são um campo vazio, mas realidades nas quais já estão acontecendo, cotidianamente.

As diretrizes curriculares nacionais para a Educação Básica, por ele já definidas, são a base para os currículos nacionais.

Currículo que contemple a participação de atores que deveriam estar no centro da formulação das políticas educacionais, junto com os estudantes, que são os/as profissionais da educação.

Currículo democrático é resultado de processo de construção democrática/ Gestão democrática.

Implantação, ainda, pactuada entre União, Estados, Distrito Federal e Municípios, no âmbito da instância nacional permanente de negociação e cooperação.

Currículo que considera o ethos dos alunos e respeita a diversidade e pluralidade das escolas brasileiras. 


\section{ANFOPE}

\author{
Fere a autonomia das instituições \\ formadoras, restringindo a \\ formação de professores em sua \\ dimensão cognitiva, a um contexto, \\ em que a educação privada e a \\ modalidade de educação a \\ distância.
}

Claro interesse em adoção de material didático previamente estabelecido, atendendo a interesses de fundações privadas.
Currículo como processo de participação democrática.

Currículo articulado - Educação Infantil e Ensino Fundamental não se separa do Ensino Médio.

Fortalecimento dos currículos locais por meio dos projetos político-pedagógicos.

Currículo e formação docente se retroalimentando.

Caráter impositivo - ameaça democrática.

Fonte: as autoras

O quadro acima apresenta uma síntese em torno das formulações e reivindicações dos movimentos em torno do que seja um currículo democrático. Os destaques são referências de lutas importantes no campo discursivo, sobretudo pelo teor de contestação e de desequilíbrio entre as ordens do discurso da BNCC.

Apple e Beane (2001), discutem sobre a ambiguidade do termo "democracia", uma vez que tem sido utilizado com frequência para justificar alguns arranjos políticos, econômicos e militares. Dessa maneira, é importante pensar o termo, não apenas como um slogan retórico. Os autores tentam estabelecer algumas condições de um processo democrático, seja pensando no aspecto mais amplo da sociedade, seja nas instituições locais e destacam o livre fluxo de ideias; o estímulo à capacidade individual e coletiva de analisar criticamente e resolver problemas; a preocupação com o "bem comum", entendido como reconhecimento da dignidade e dos direitos de todos os indivíduos e, sobremaneira, dos grupos minoritários, entre outras.

Eles consideram que, escolas democráticas resultam, dentre outros fatores, de apostas práticas dos educadores para redimensionar o controle centralizado. Assim, a padronização dos conteúdos e do modo de avaliar, não se reduz, portanto, a uma autonomia delegada. Ao entendermos o currículo na proposição de um projeto políticopedagógico, teríamos uma ferramenta importante para conquista e efetivação de práticas mais autônomas de construção do conhecimento escolar.

Assim, a partir de Fairclough (2001, p.126) entendemos as contestações apresentadas pelas entidades representativas e históricas sobre a BNCC em seu modus 
operandi representam um "modo de luta hegemônica, que reproduz, reestrutura ou desafia as ordens de discurso existentes". A abordagem de análise da linguagem, tem sido útil aos estudos de mudança cultural e social, especificamente quando um texto quer ordenar uma forma de anunciar um objeto, no caso da BNCC sob uma pseudodemocracia. Compreendemos que os discursos são "modos de ação, uma forma através da qual as pessoas podem agir sobre o mundo e, especialmente, sobre os outros, como também um modo de representação"; o discurso pode ser "moldado e restringido pela estrutura social", enquanto significa e produz significados. Nessas contestações foi possível vislumbrar múltiplos significados o que pode auxiliar tomadas de posição referentes ao texto e ao processo de produção da BNCC.

\section{Considerações finais:}

Concluímos reafirmando que as políticas não são, nem podem ser concebidas, exclusivamente na esfera governamental, assim entendemos que a versão final da BNCC, mesmo não sendo resultado das discussões tecidas, em seu processo, por algumas instituições educacionais, ela não é capaz de corresponder a totalidade da política curricular brasileira, antes ela será, como dito na introdução, reinterpretada e reinventada nos contextos plurais. O processo não se dá de maneira simples e anacrônica, mas se constitui, à revelia das correntes mais tradicionais e conservadoras, em processo complexo, polífono e multifacetado que envolve contextos e culturas diversas - num processo não linear e não hierárquico.

Os documentos apresentados como forma de resistência e contestação pelas entidades e fórum contemplam sentidos de democracia a partir de suas perspectivas epistemológicas, mas há demandas comuns entre as formas de perceber um currículo mais democrático. A ideia de participação dos sujeitos/atores no processo de pensar um currículo, mesmo na perspectiva de negação de um currículo homogêneo e nacional, é bem representada. Algumas entidades recuperam as bandeiras e lutas históricas que foram travadas para que algumas conquistas fossem possíveis. A laicidade, gratuidade e diversidade da educação pública são significantes conclamados nas contestações.

Entendemos que a BNCC não é um documento de discurso homogêneo. O texto contempla leituras progressistas e de anúncio de autonomia curricular, ao mesmo tempo que subtrai os sentidos amplos da compreensão de gênero, evidenciando apenas a perspectiva textual da linguagem. $\mathrm{O}$ discurso se encaminha contemplando processos de 
interdiscursividade, ou seja, apropriação de textos outros para justificar sua proposição.

O contexto de produção documental revela que a hegemonia numa perspectiva de análise crítica do discurso é um processo de construção de alianças e integração de lutas, não uma dominação de um grupo subalterno em busca de consentimento, mas revela-se como foco de luta constante em torno da participação democrática nos rumos do currículo nacional.

Acreditamos que cada um dos documentos, aqui analisados, apresentam em seu teor a concepção de currículo e política das entidades e associações. Através desses documentos temos, também, disputa de poder que se configuram na forma de tensões discursivas e intentam a hegemonização de sentidos, pois o currículo, conforme considera Silva (2003) é esse campo de disputas, nunca neutro.

Como pesquisadoras do campo do Currículo, compreendemos que qualquer ação, movimento, endereçamento de produção de conhecimento é também currículo. A Base é uma política de currículo e afirma quais são os conhecimentos/aprendizagens "mais importantes" para a formação do homem brasileiro. Idealiza um tipo de cidadania e prevê, inclusive, um processo de avaliação em larga escala mais justo a partir de parâmetros comuns/nacionais. Não podemos dizer que Base não é currículo. A Base se impõe como um Currículo Nacional que prevê direitos de aprendizagem, o que não elimina a recriação, reinvenção, reposição do currículo real na escola, na sala de aula.

A BNCC, de acordo com o texto da terceira e última versão, bem como os documentos de repúdio aqui apresentados, se constitui elementos de poder ao passo que buscam a partir de seus discursos legitimar um lugar de fala e identidade, que não consegue corresponder a inteireza e singularidades do outro a quem esse currículo diz se endereçar, mas não consegue contemplar. Há diferenças que não são consideradas nos documentos, há espaços e identidades que fazem currículo independente das intenções da BNCC, é momento de indagar quem são esses outros que a base não consegue alcançar? A quem foi outorgado o poder de dizer o que é currículo? Ao passo que possuo assertivas sobre o conceito do que é currículo e o que o constituí, eu engesso e desconsidero tudo que dessa concepção destoa.

No campo do Currículo e nas experiências de Base Nacional pelo mundo afora, as pesquisas demonstram que os currículos praticados pelos alunos e professores, afirmam e também rejeitam princípios norteadores nacionais. Eles mais rejeitam e forjam, sobretudo aquilo a que não tiveram participação e nem concederam sua anuência. O sentimento de 
pertencimento dos docentes em uma política curricular é fundamental para que essa política tenham um bom alcance. A experiência do assembleísmo em torno da produção de um currículo nacional não tem logrado êxito. É preciso alargar a participação dos sujeitos do processo, sobretudo os sujeitos do chão da escola.

Assim, retomando a Hamlet e a constante reflexividade do seu pensamento, talvez não seja preciso definir, em última instância, o currículo, mas problematizá-lo, sair do trono para dar substância às lutas que continuam em processo. Nesse momento é bom lembrar a clássica frase do personagem mais famoso de Shakeaspeare: "há algo podre no reino da Dinamarca". Sentimos o cheiro de excrementos na política curricular do Brasil.

\section{REFERÊNCIAS}

ALBINO, A. C. A. Projeto Político-Pedagógico em Enunciação Política: Uma análise da prática discursiva docente. 141f. Dissertação de Mestrado João Pessoa. Universidade Federal da Paraíba - UFPB, 2010.

ALBINO, A. C. A Currículo e autonomia docente: enunciações políticas. 1 ed. Curitiba: Appris, 2018.

APPLE, M.. A política de conhecimento oficial: faz sentido a ideia de um currículo nacional? In: MOREIRA, A. F.; TADEU, T. (Org.). Currículo, cultura e sociedade. São Paulo: Cortez, 2011.

2006.

Ideologia e currículo; tradução Vinícius Figueira. - Ed. Porto Alegre: Artmed,

ANFOPE - Associação Nacional pela Formação dos Profissionais da Educação. Posição da ANFOPE sobre a BNCC. Repúdio ao processo de elaboração, discussão e aprovação da BNCC e a sua implementação. 2017. Disponível em: https://avaliacaoeducacional.files.wordpress.com/2017/09/nota-anfope-repudia-a-bncc.pdf . Acesso em: 25/02/2019.

ANPAE - Associação Nacional de Política e Administração da Educação. Nota das entidades sobre a audiência pública do CNE sobre a BNCC do Ensino Médio https://www.anpae.org.br/website/noticias/427-2018-06-12-15-28-14. Acesso em 25/02/2019.

ANPEd - Associação Nacional de Pós-Graduação e Pesquisa em Educação. Nota da ANPEd sobre a entrega da terceira versão da Base Nacional Comum Curricular (BNCC) ao Conselho Nacional de Educação (CNE), 2017. Disponível em: http://www.ANPEd.org.br/news/nota-da-ANPEd-sobre-entrega-da-terceira-versao-dabase-nacional-comum-curricular-bncc-ao Acesso em: 25/02/2019.

BRASIL. Base Nacional Comum Curricular: Educação Infantil e Ensino Fundamental. Brasília: MEC/Secretaria de Educação Básica, 2017. 
BRASIL. Base Nacional Comum Curricular: Ensino Médio. Brasília: MEC/Secretaria de Educação Básica, 2018.

BRASIL. Constituição Federal, 1988.

BRASIL. Lei de Diretrizes e Bases da Educação Nacional. Lei número 9394, 20 de dezembro de 1996

Manifestação das entidades educacionais sobre a política de formação de professores anunciada pelo MEC. 2018.2 Disponível em: http://www.ANPEd.org.br/news/manifestacao-das-entidades-educacionais-sobre-politicade-formacao-de-professores-anunciada. Acesso em: 25/02/2019.

FAIRCLOUGH, N. Discurso e Mudança Social. Tradução de Izabel Mabalhães. Editora: Universidade de Brasília, 2001.

FAIRCLOUGH, N. Language and power. London: Longman, 1989.

Fórum Nacional Popular de Educação- FNPE. Nota Pública: Brasília, setembro de 2018. Disponível em: http://fnpe.com.br/nao-ha-discussao-curricular-seria-e-consequente-comexclusao-de-educadores-as-e-com-rebaixamento-do-direito-de-estudantes/ . Acesso: janeiro de 2019.

FREITAS, L. C.. BNCC: uma base para o gerencialismo-populista. Blog Avaliação Educacional. Disponível: https://avaliacaoeducacional.com/2017/04/07/bncc-uma-basepara-o-gerencialismo-populista/ acesso em fevereiro de 2019.

FRANGELLA, Rita de Cássia. Políticas de formação do alfabetizador e produção de políticas curriculares: pactuando sentidos para formação, alfabetização e currículo. Práxis Educativa (UEPG. Online), v. 11, p. 107-128, 2015.

GRAMSCI, A. A Gramsci reader: selected writings, 1916-1935. Organizado por David Forgacs. London: Lawrence and Wishart, 1988.

Concepção dialética da história. Tradução de Carlos N. Coutinho. Rio de Janeiro: Civilização Brasileira, 1995 [1955].

MACEDO, E. F. de. Currículo: Política, Cultura e Poder. Currículo sem Fronteiras, v. 6, n. 2, p. 98-113, jul./dez. 2006.

Base Nacional Curricular Comum: novas formas de sociabilidade produzindo sentidos para a educação. Revista e-Curriculum, São Paulo, v. 12, n. 03 p.1530 - 1555, out./dez. 2014.

MOREIRA, A. F. B.; SILVA, T. T. (Org.). Currículo, cultura e sociedade. 2. ed. São Paulo: Cortez, 1997.

PEREIRA, M. Z. C. Currículo e Autopoiése. João Pessoa: Editora Universitária da UFPB. 2010. 
SANTOS, B. S. Reconhecer para libertar: os caminhos do cosmopolitanismo multicultural. Rio de Janeiro: Civilização Brasileira, 2003.

SILVA, T. T. Documentos de Identidade: Uma introdução às teorias do currículo. 2. ed., $5^{\text {a }}$ reimp. - Belo Horizonte: Autêntica, 2003.

SÜSSEKIND, Maria Luiza. As (im)possibilidades de uma Base Comum Nacional. Revista e-Curriculum, São Paulo, v. 12, n. 03 p.1512 - 1529, out./dez. 2014.

Recebido: 05/03/2019

Aceito: 30/03/2019 